\title{
THE MIDDLE AORTIC SYNDROME
}

\author{
BY \\ P. K. SEN, S. G. KINARE, S. D. ENGINEER, AND G. B. PARULKAR \\ From the Department of Surgery, Seth G. S. Medical College and K.E.M. Hospital, Bombay 12, India
}

Received January 12, 1963

Obstructive lesions of the aorta and its branches have been the subject of a great deal of interest and study due to the phenomenal growth of vascular surgery in recent years. With this study has come about a constant reappraisal of our clinical knowledge of these cases. Congenital narrowings of the aorta are nearly all located in the isthmial area, and clinical knowledge of these cases is based upon well-recorded and critically documented writings of many workers. The aortic blocks of acquired origin are, however, still the subject of intensive study and within the past decade clearly defined clinical syndromes have been described, depending on the site of the block. The two best known are the aortic arch syndrome of Takayasu (1908), or Martorell and Fabré Tersol (1944) and the terminal aortic (bifurcation) syndrome of Leriche and Morel (1948) (Fig. 1).

With increasing safety and facility in the use of aortography for the diagnosis of a large number of conditions (apart from those directly vascular), blocks in the middle segment (between the arch and the terminal bifurcation of the aorta) are being diagnosed with greater frequency. The patho-

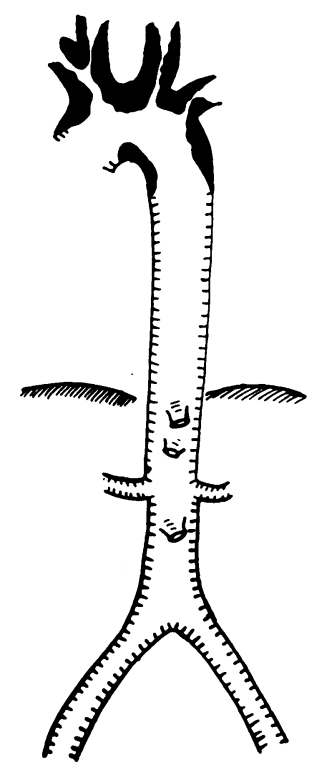

Aortic Arch Syndrome (Martorell or

Takayasu's Syndrome)

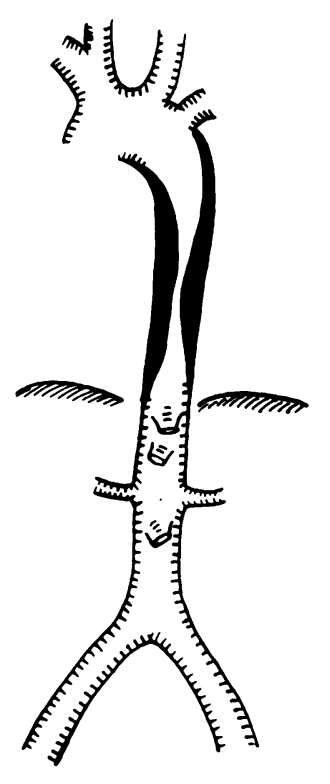

"Middle Aortic" Syndrome (Supradiaphragmatic)

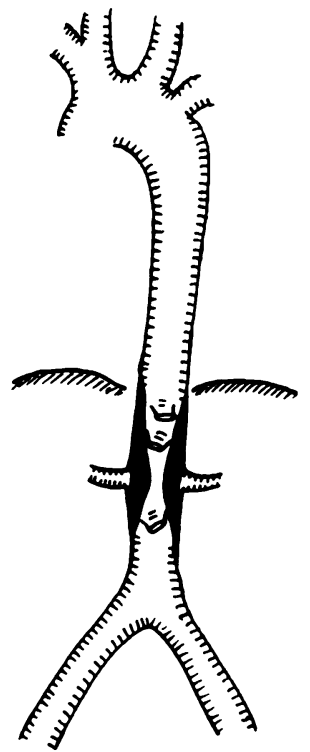

"Middle Aortic" Syndrome (Infradiaphragmatic)

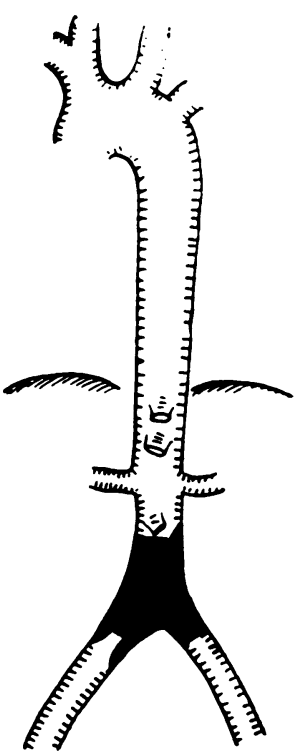

Aortic Bifurcation Syndrome FIG. 1.-Diagrammatic representation of the aortic obliterative syndromes. 
logical nature of these acquired blocks is not always clear. From the study of earlier reports on this subject and our own experience it appears, in a superficial study at least, that the preponderant lesion varies and depends on the site of obstruction.

During the past three years at the K.E.M. Hospital, Bombay, we have come across 16 cases of what we now have come to call "the middle aortic syndrome." The clinical study of these subisthmial blocks, which in all cases have been caused by a non-specific stenosing aortitis, is the subject of this present communication. The nature of the pathological lesion and its possible relation to tuberculosis have already been reported by us (Sen et al., 1962). It is our submission that the clinical characteristics of this syndrome have been shown to be sufficiently typical and repetitive to be given the name of this separate syndrome, which is not only clinically but perhaps even pathologically and pathogenetically significant.

The typical patient is a young woman below the age of 25 years who complains of symptoms of hypertensive disease or, less frequently, of lower limb claudication or abdominal angina. Most of them superficially resemble cases of coarctation of aorta and are diagnosed as such, while the remainder are diagnosed as suffering from essential hypertension. The unusual nature of the block in the aorta is indicated by absent or weak pulse in one or both superior extremities, and a bruit heard over the abdomen or in the interscapular region lower down than is usually heard in congenital coarctation. The pathology of this block seems to be some sort of non-specific allergic panarteritis of a segmental nature involving the middle part of the aorta-more often supradiaphragmatic but not infrequently infradiaphragmatic, and occasionally both. Involvement of the renal arteries is an additional factor responsible for hypertension in some cases. An active tuberculous lesion elsewhere in the body is found in most cases, and this may possibly be an allergen. Clinical evidence of such a focus strengthens the diagnosis of middle aortic syndrome.

Of the 16 cases, 14 were studied clinically in detail and the exact diagnosis was arrived at by angiography: in two of these necropsy findings were available later. Two other cases in which the aortic lesion was not diagnosed clinically were discovered from a study of past necropsy records and specimens.

TABLE I

Age ANd Sex Distribution

\begin{tabular}{c|c|c|c}
\hline Age-group (yr.) & No. of cases & Male & Female \\
\hline $1-5$ & 1 & - & 1 \\
$6-10$ & 3 & $\frac{1}{1}$ & 1 \\
$11-15$ & 1 & 2 \\
$16-20$ & 3 & 2 & 4 \\
$21-25$ & 2 & - & 2 \\
$26-30$ & 2 & & \\
\hline
\end{tabular}

\section{Clinical Features}

The age and sex distribution of the cases are shown in Table I. All the patients were below the age of 30 with more than half between 16 and 25 years. The youngest patient was a 3-year-old child. Women were predominantly affected and constitute 75 per cent of the total.

Signs and Symptoms. The presenting symptoms are summarized in Table II. About half the patients sought medical advice after the cardiac failure had set in. The preceding symptoms were less definite and were probably ignored. Intermittent claudication was complained of by only two patients. Chronic abdominal pain was the main symptom in three and it was unaccompanied by any other symptoms indicative of aortic disease. 
TABLE II

Presenting Symptoms

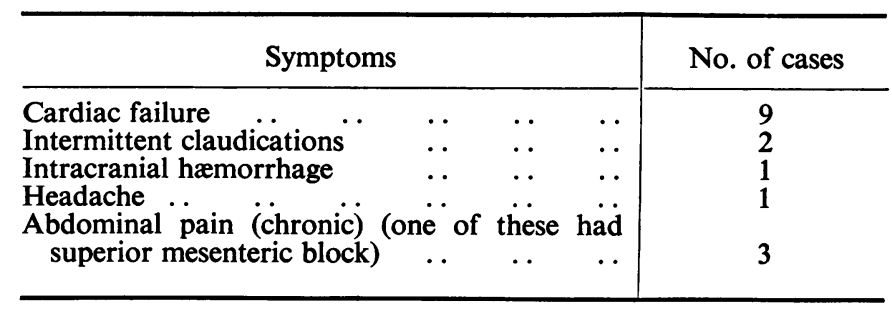

TABLE III

Cardiovascular Studies

\begin{tabular}{|c|c|}
\hline & No. of cases \\
\hline 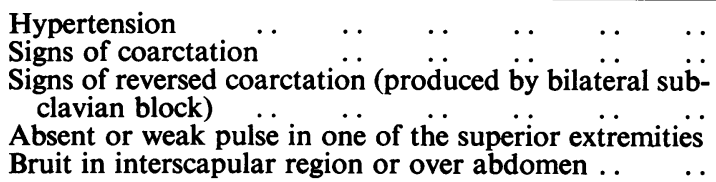 & $\begin{array}{l}16 \text { (all cases) } \\
11 \text { (well marked, 9; doubtful, 2) } \\
1 \\
5 \text { (right, } 3 \text {; left, 2) }\end{array}$ \\
\hline
\end{tabular}

Systemic hypertensive symptoms were present in all instances and the discovery of high blood pressure was the main reason leading to detailed cardiovascular studies in most of them (Table III). Absent or weak pulsations in both the inferior extremities were noticed in more than half of the cases. Some of them were sent with the diagnosis of congenital coarctation, but the absence or weakness of the pulse in one or both superior extremities aroused some suspicion about the exact nature of the disease. The most helpful sign was the presence of a bruit in the interscapular region lower down or over the abdomen, which indicated a low level block.

Lesion in the Aorta. The lesion in the aorta was studied at necropsy in four patients. In 12 the diagnosis was based on angiography. Seven of them were subjected to some sort of operative procedure and the aorta could be examined on the operation table. The lesions found could be divided into three morphological types though all offered identical histological pictures. The first and most common (seen in 12 patients) was stenosis of a segment of the aorta involving the supradiaphragmatic or infradiaphragmatic portions (Fig. 2). The block was incomplete in the majority. In one case there were two stenosed segments-supradiaphragmatic and infradiaphragmatic - with a comparatively normal stretch of aorta between (Fig. 3). The gross appearance of the vessel in all these cases was the same. The external diameter of the aorta was not reduced to a great extent but there were significant and often conspicuous peri-aortic adhesions. The involved segment often appeared solid on palpation and cross-section of it revealed notable thickening of the adventitial as well as the intimal coats resulting in much narrowing of the lumen. Superadded thrombosis was seen in every case that was examined at necropsy.

In the second type diffuse involvement of the major portion of the descending aorta was seen showing gross irregularity and small sacculations in addition to stenosis. One of the two patients with this type of lesion was explored, and showed extensive and diffuse calcification of the aortic wall (Fig. 4).

The third type, which probably represents an earlier stage of the second type, presented segmental thickening of the wall of the aorta with saccular dilatations, and there was no narrowing of the lumen at all. This was seen in two patients (Fig. 5 and 10). One of them was a 3-year-old girl who 


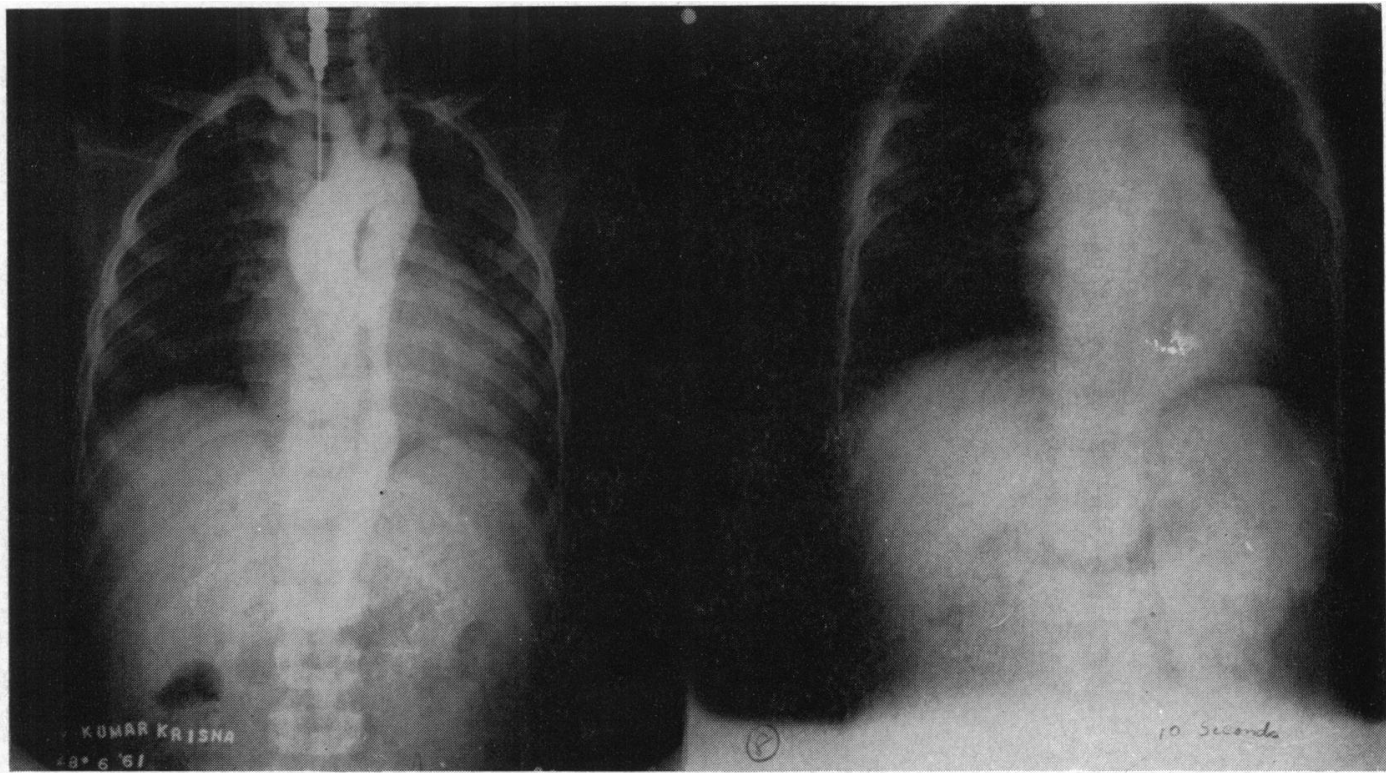

A

Fig. 2.-Aortogram showing typical stenosis of mid-thoracic segment. (A) Before operation. (B) After operation-showing functioning bypass.

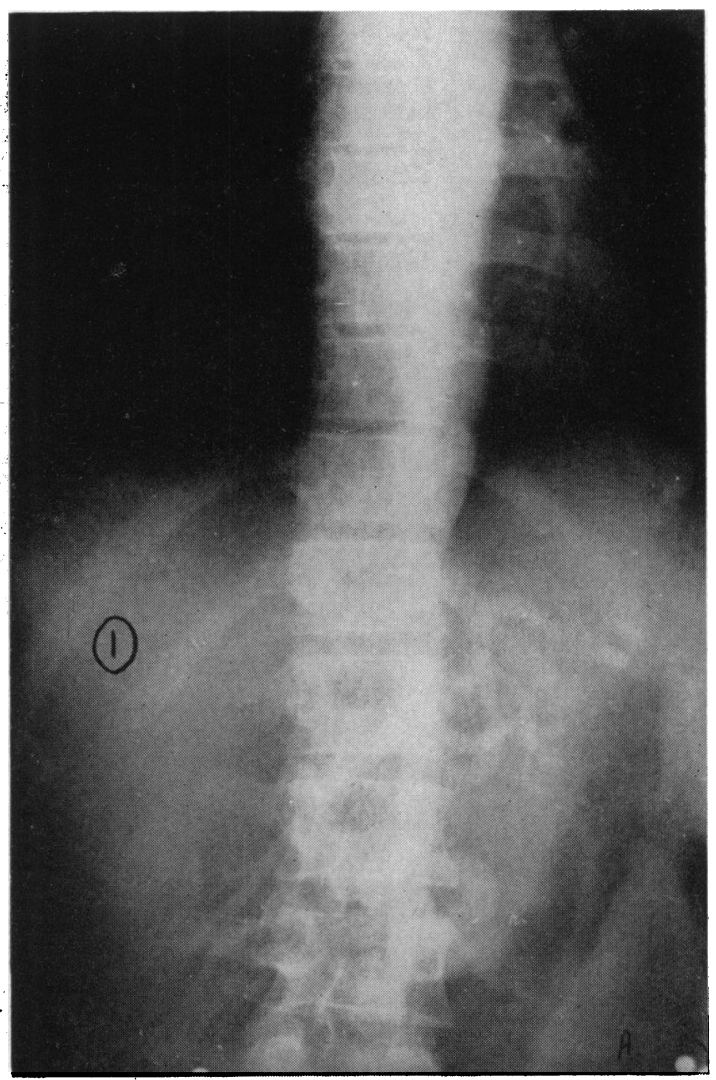

FIG. 4.-Aortogram showing diffuse involvement of aorta.
FIG. 3.-Aortogram showing two stenosed segments (supradiaphragmatic and infradiaphragmatic) with normal aorta between.

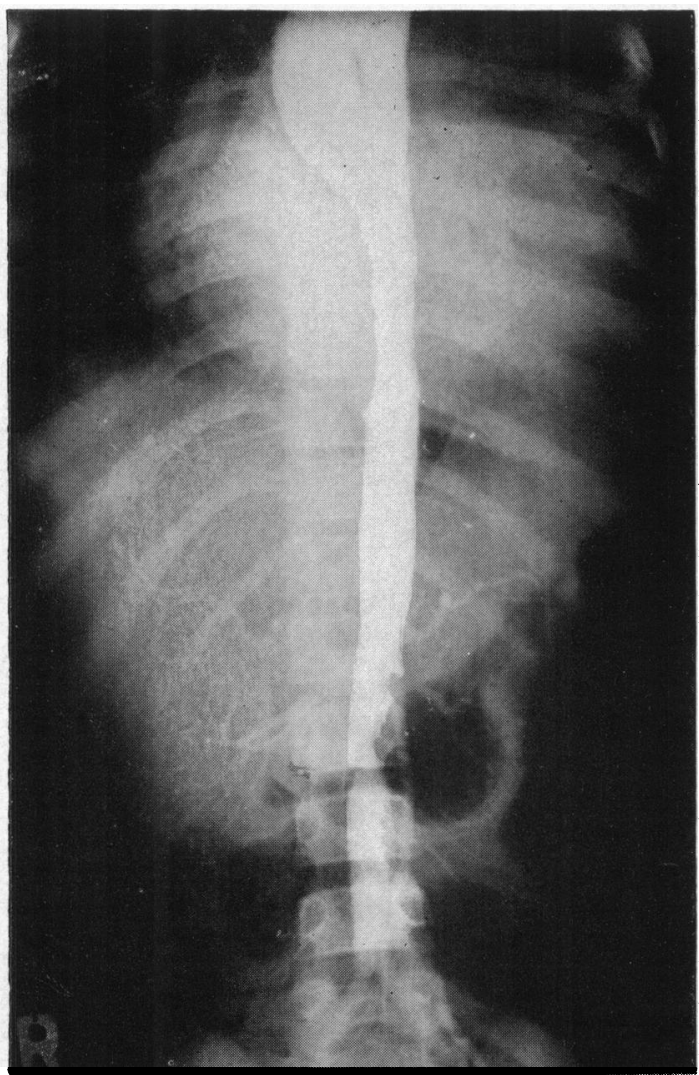




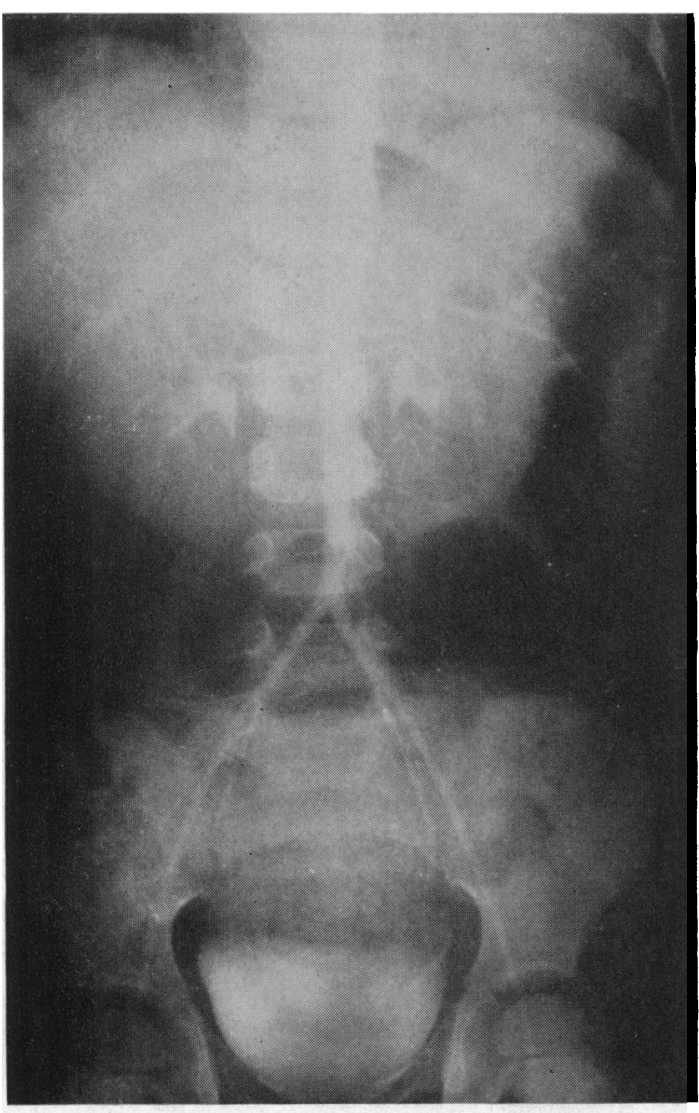

FIG. 5.-Aortogram showing very early sacculation in the abdominal aorta with stenosis of the left renal artery.

TABLE IV

FrequenCy of INVOLVEMENT OF BRANCHES OF THE AORTA

\begin{tabular}{|c|c|c|c|c|c|c|}
\hline & & & & & & No. of cases \\
\hline \multicolumn{6}{|c|}{ Subclavian } & \multirow{3}{*}{$\begin{array}{l}2 \\
5\end{array}$} \\
\hline Right & . & $\cdots$ & .. & . & . & \\
\hline Left & $\ldots$ & $\ldots$ & .. & .. & .. & \\
\hline \multicolumn{6}{|c|}{ Carotid } & \multirow{4}{*}{$\begin{array}{l}1 \\
4 \\
3\end{array}$} \\
\hline Left $(p$ & artial) & . & .. & .. & $\ldots$ & \\
\hline Coliac & .. & $\ldots$ & .. & .. & .. & \\
\hline Superior & mesente & eric & .. & .. & .. & \\
\hline \multicolumn{6}{|c|}{ Renal } & \multirow{3}{*}{$\begin{array}{l}2 \\
5\end{array}$} \\
\hline Right & . & .. & .. & . & .. & \\
\hline Left & . & . & .. & . & . & \\
\hline
\end{tabular}
other but with more than one ætiological basis. Until such time as ætiological identification becomes possible, the classification of these disorders will depend mainly upon the clinical syndrome produced, as histopathological reactions are more or less the same. 


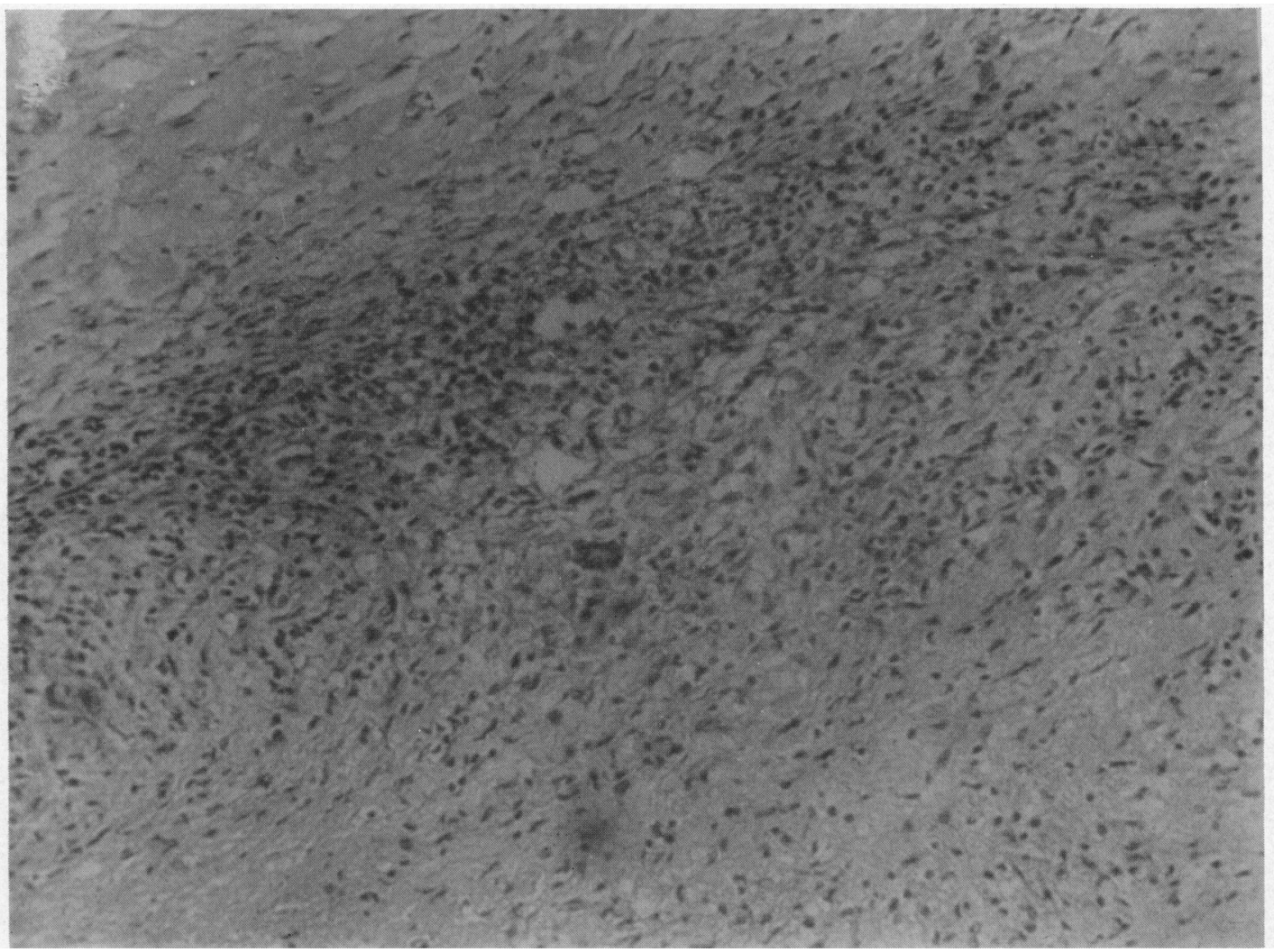

Fig. 6. - Photomicrograph showing the inflammatory reaction seen in the media of the aorta (H. and E. $\times 260$.).

The 16 patients on whom this paper is based fall into a relatively composite and distinct groupclinically, radiologically, and possibly even in terms of pathogenesis. They may easily be differentiated from cases of congenital coarctation which they superficially resemble. Clinically, they have absent or weak pulses in one of the arms in association with a murmur heard over the lower part of the trunk (epigastrium or lower part of the back). Rarely, hypoplasia of the subclavian artery

TABLE V

THERAPY

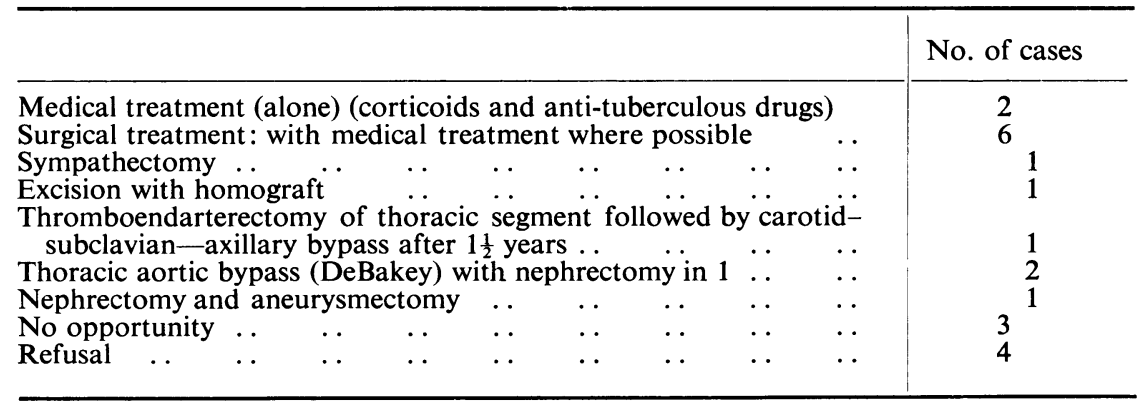




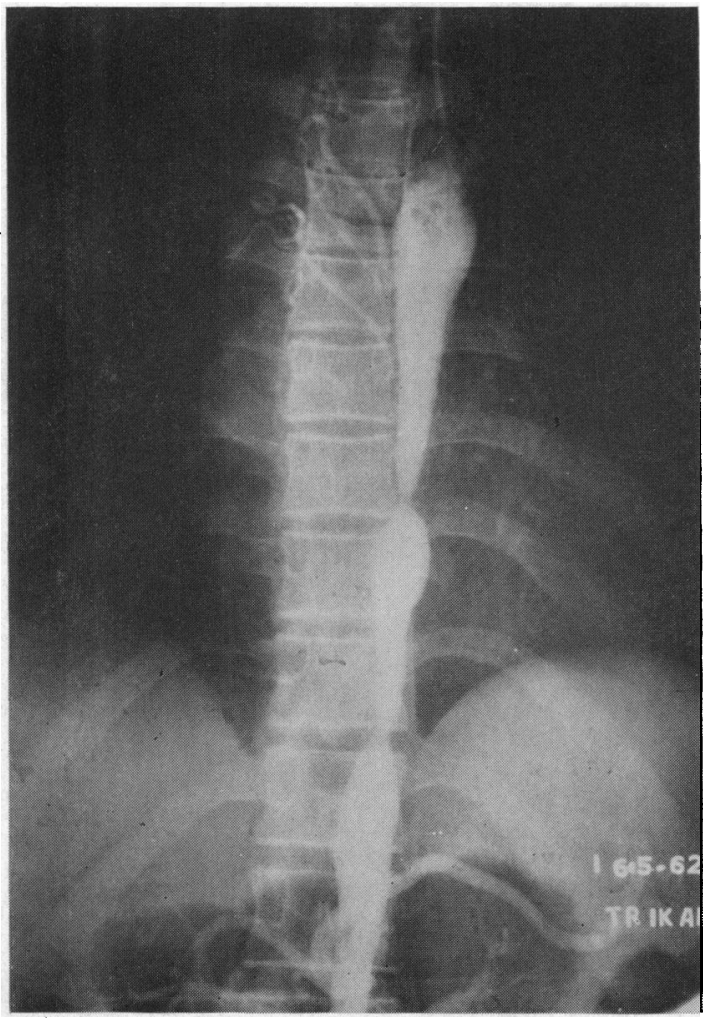

FIG. 7.-Aortogram showing two constrictions in the descending thoracic aorta. The patient is a man aged 22 years who was referred with a diagnosis of congenital coarctation.

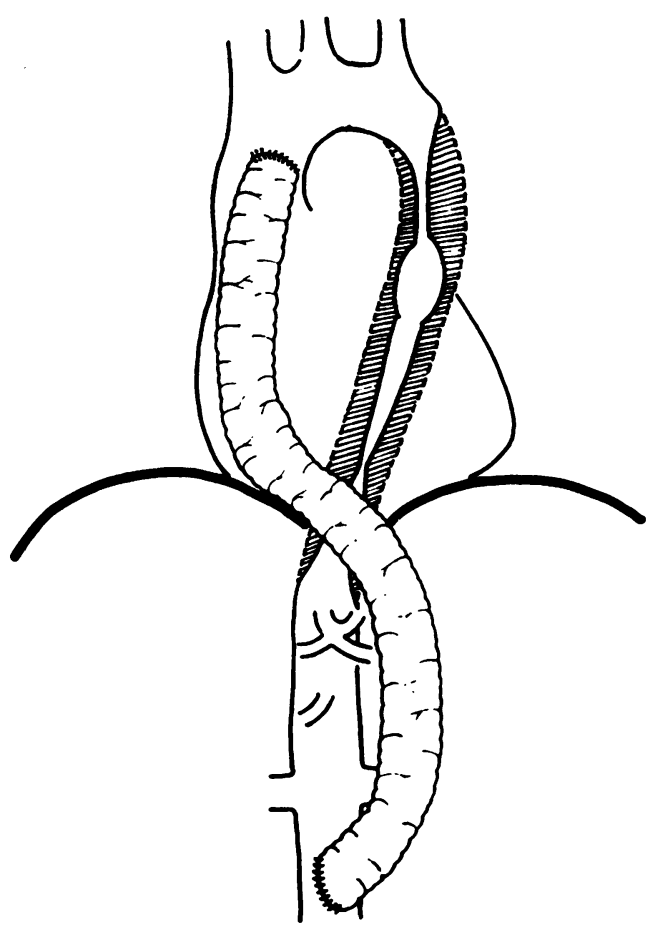

FIG. 8.-Diagrammatic representation of the dacron graft anastomosed with the ascending aorta and abdominal aorta below the level of renal arteries to bypass the stenosed aortic segment depicted in Fig. 7.

associated with an infantile type of coarctation may give difficulty in diagnosis but the lower level of the block indicated by the murmur helps to exclude this.

Radiologically, the elongated type of narrowing and absence of rib notching distinguishes it from congenital coarctation (Fig. 7). Absence of prominent intercostal collaterals in this type of block is due to the more extensive inflammatory involvement of the aorta blocking the origins of intercostal arteries.

Congenital coarctation usually produces a very localized ring-like stenosis unlike the irregular elongated narrowing seen in our patients. However, there are cases reported of congenital elongated coarctation involving the mid-thoracic aorta (Milloy and Fell, 1959). The diagnosis in them will be essentially histological, but they must be very rare. In fact, in our experience, the incidence of this type of stenosing aortitis appears to be greater than that of congenital coarctation. During the period under discussion, when these 16 cases were discovered, only 4 examples of congenital coarctation were observed, and so far no case from our records of congenital coarctation shows an elongated type of narrowing.

There are several isolated case reports describing lesions similar to those found in our patients; they have been mainly reported as coarctation at an unusual site (Bahnson, Cooley, and Sloan, 1949; Konar, Chaudhury, and Basu, 1955). Histopathological study was not available in all these but wherever available it indicates an acquired lesion of inflammatory type. Since all these were isolated case reports no attempts have been made to define the clinical picture or ætiology. More 


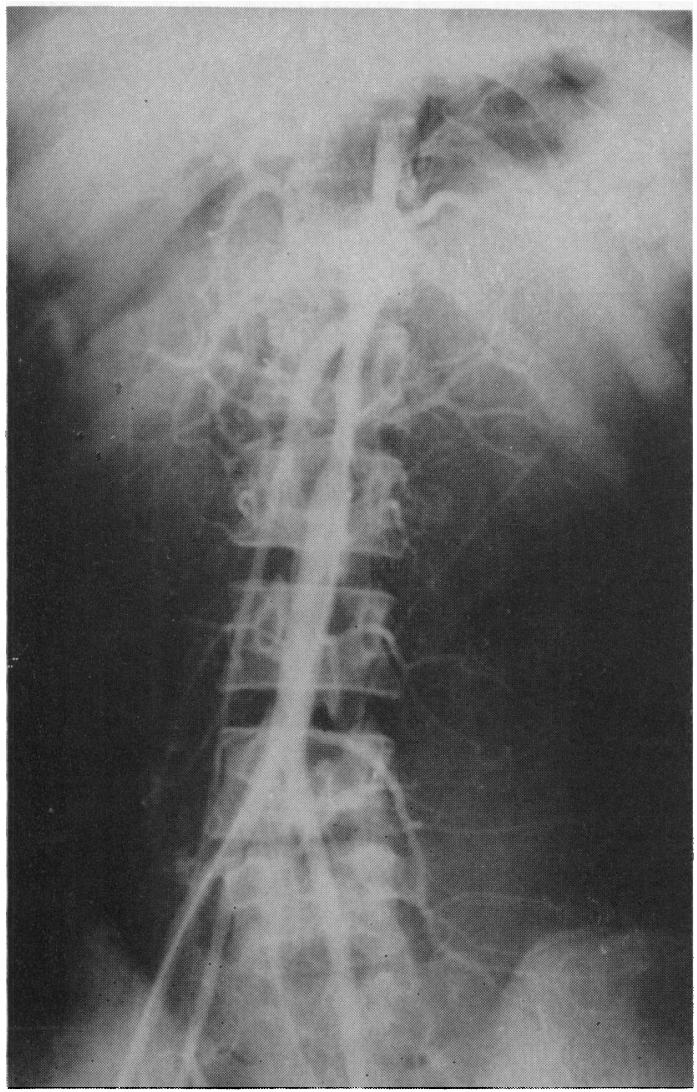

FIG. 9.-Aortogram showing involvement of lower thoracic and upper abdominal aorta with two constrictions. Tuberculous process affecting the bodies of 4 th and 5 th lumbar vertebræ is also evident. Patient was a woman of 30 .

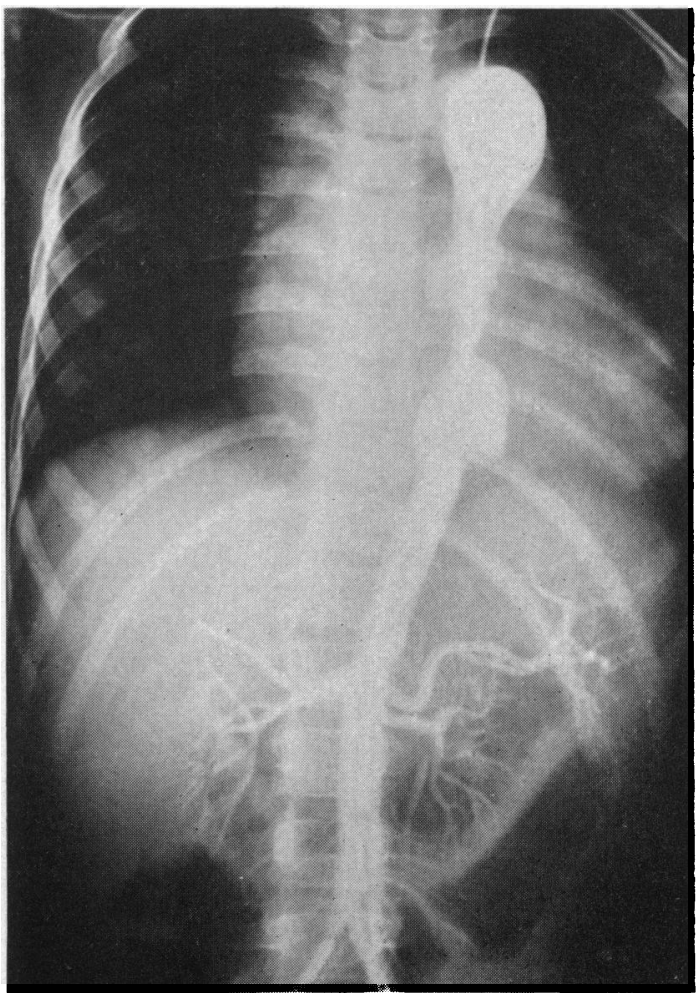

FIG. 10.-Aortogram of a girl aged 10 years showing disease of descending thoracic aorta producing stenosis with aneurysmal sacculations.

over, these were reported when aortitis apart from syphilis was rather an unknown entity. Cases described later by Lomas, Bolande, and Gibson (1959) and Danaraj and Wong Hee Ong (1959) were reported as primary arteritis of the aorta.

Since the publication of Scimizu and Sano's (1951) paper on pulseless disease there have been many case reports of pulseless disease or the aortic arch syndrome. Though most of our patients showed absent or weak pulses in the arms they did not exhibit other features of the aortic arch syndrome, as carotid block was uniformly absent, except a partial one in one of our late cases. However, recently Inada et al. (1962) have described cases with a combination of arch syndromes and stenosis of the descending aorta, which suggests some correlation between the two; they mention a similar view being expressed in two cases of atypical coarctation in Japan.

The possible role of tuberculosis in these cases will remain a point of issue as tuberculosis is unfortunately only too common in the hospital patients of the city of Bombay. However, the presence of active tuberculous infection in 12 out of these 16 cannot be easily regarded as fortuitous (Fig. 9). In two a successful search for a tuberculous lesion was made after the vascular lesion was diagnosed.

Treatment with anti-tuberculous drugs and corticoids produced some beneficial effects in a few patients though this impression is mainly empirical. In the diagnosis of this syndrome however it seems pertinent to include the association of tuberculosis, at least in this part of the world. 
It is extremely difficult to state anything about the natural history of the disease at the present stage for most of our cases presented themselves after some complication of hypertensive disease had set in. The earliest lesion was seen in our youngest patient aged 3 years. The maximum period under observation so far has been three years, in a case which has shown progressive changes in spite of anti-tuberculous drugs and corticoids. Yet another patient who has been under observation for one and a half years has shown no progress in the disease so far. It appears that the disease is not constant in its progress and may remain static for long periods, with exacerbations and even remissions.

\section{SUMMARY}

A clinico-pathological study has been made of 16 cases of inflammatory disease of the aorta in which the middle portion of the vessel (between the arch and bifurcation) is involved. In almost all the patients the disease produced constriction in the aorta and a specific symptom-complex which we designate as the "middle aortic syndrome."

The disease is seen in children and young adults, predominantly affecting the female sex who presented with symptoms of hypertensive disease or lower limb claudication or abdominal angina. Most of them were diagnosed as having congenital coarctation, a condition to which there was a superficial resemblance. The suspicion of the unusual nature of the disease was usually aroused by the presence of a weak pulse in one or other superior extremity, and a low-placed systolic murmur over the dorsum or abdomen. On aortography a localized irregularity with constriction was seen in the mid-thoracic region in most of the cases and in the abdominal portion in some; occasionally, diffuse involvement with calcific changes was seen. Aneurysmal dilatations were seen in a few instances. Histological examination of the aorta showed a non-specific aortitis, probably of allergic origin. An associated tuberculous focus elsewhere (lung, liver, lymph nodes) in 75 per cent of these cases suggested tubercle bacillus as a possible allergen. Surgical bypass procedures have been employed successfully in relieving the symptoms.

\section{REFERENCES}

Bahnson, H. T., Cooley, R. N., and Sloan, R. D. (1949). Coarctation of the aorta at unusual sites. Amer. Heart J., 38, 905.

Danaraj, T. J., and Wong Hee Ong (1959). Primary arteritis of abdominal aorta in children causing bilateral stenosis of renal arteries and hypertension. Circulation, 20, 856.

Inada, K., Shimizu, H., Kobayashi, I., Ishiai, S., and Kawamoto, S. (1962). Pulseless disease and atypical coarctation of the aorta. Arch. Surg., 84, 306.

Konar, N. R., Chaudhury, D. C. R., and Basu, A. K. (1955). A case of coarctation of aorta at an unual site Amer. Heart J., 49, 275.

Leriche, R., and Morel, A. (1948). The syndrome of thrombotic obliteration of the aortic bifurcation. Ann. Surg., $127,193$.

Lomas, R. W., Bolande, R. P., and Gibson, W. M. (1959). Primary arteritis of the aorta in a child. Amer. J. Dis. Child., $97,87$.

Martorell, F., and Fabré Tersol, J. (1944). El síndrome de obliteración de los troncos supraaorticos. Med. clín. (Barcelona), 2, 26.

Milloy, F., and Fell, E. H. (1959). Elongate coarctation of the aorta. A.M.A. Arch. Surg., 78, 759.

Sen, P. K., Kinare, S. G., Kulkarni, T. P., and Parulkar, G. B. (1962). Stenosing aortitis of unknown ætiology. Surgery, 51, 317.

Scimizu, K., and Sano, K. (1951). Pulseless disease. J. Neuropath. clin. Neurol., 1, 37. Abstract in J. Amer. med. Ass., 145, 1095 (1951).

Takayasu, M. (1908). A case with peculiar changes of the central retinal vessels. Acta. Soc. Ophthal. Jap., $12,554$. 